\title{
VIRTUAL TARGET CONSTRUCTION FOR STRUCTURE-BASED SCREENING IN THE DISCOVERY OF HISTAMINE $\mathrm{H}_{2}$ RECEPTOR LIGANDS
}

\section{GERRY NUGRAHA ${ }^{1,2}$, ENADE PERDANA ISTYASTONO1*}

\author{
1Faculty of Pharmacy, Universitas Sanata Dharma, Yogyakarta, ${ }^{2}$ Pharmacy, STIKES ‘Aisyiyah, Palembang
}

Email: enade@usd.ac.id

Received: 23 Feb 2021, Revised and Accepted: 23 Mar 2021

\section{ABSTRACT}

Objective: This study aimed to develop validated targets to be employed in structure-based virtual screening (SBVS) to discover ligands for the human histamine $\mathrm{H}_{2}$ receptor (hHRH2).

Methods: The virtual targets construction was initiated by homology modeling with the reference compound ranitidine as the ligand followed by 100 ns molecular dynamics (MD) simulations. During MD simulations, the snapshot with the lowest value of the free energy of binding was selected for further validation by re-docking simulations. All simulations were performed in YASARA-Structure.

Results: The research presented here resulted in one validated target for the SBVS. Additionally, by employing a clustering module in MD simulations analysis in YASARA-Structure, more than ten different virtual targets are also available for further uses.

Conclusion: The virtual targets resulted in this research offer possibilities to construct valid SBVS protocols to identify ligands for the hHRH2.

Keywords: Histamine $\mathrm{H}_{2}$, Ranitidine, Homology modeling, Molecular docking, Molecular dynamics

(C) 2021 The Authors. Published by Innovare Academic Sciences Pvt Ltd. This is an open access article under the CC BY license (https://creativecommons.org/licenses/by/4.0/) DOI: https://dx.doi.org/10.22159/ijap.2021v13i3.41202. Journal homepage: https://innovareacademics.in/journals/index.php/ijap

Histamine $\mathrm{H}_{2}$ receptor (HRH2) plays an essential role in regulating gastric acid, the secretion of which facilitates protein digestion [1]. The receptor contributes to the absorption of micronutrients and certain drugs, eliminating ingested microorganisms and preventing bacterial overgrowth and enteric infections [2]. Receptor therapy contributes in treating peptic ulcers and gastro-oesophageal reflux disease (GORD) [1]. This disease is a global health epidemic, with billions of people suffering from gastric disorders to gastric cancer [3].

Due to these significant roles, it is necessary to perform research regarding the human HRH2 (hHRH2) as the target of drug discovery projects [4]. One of the effective methods in the computer-assisted discovery of new drugs is structure-based virtual screening (SBVS) [5]. The approach is efficient for the design, discovery, and optimization of bioactive compounds [6] and is capable of generating directions for further drug development [7], projecting the ligand binding pose, estimating its affinity for the target protein [8], modeling accurate structures, and predicting activity precisely [9].

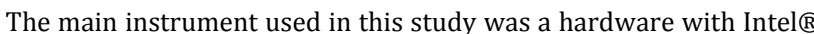
Xeon 2680 V3 as the processor, Nvidia Quadro M4000 as the video graphic card, 500Gb SSD, 64Gb ECC Registered RAM. The operating system was Ubuntu 20.04.1 LTS, and the main software was YASARA-Structure 20.1.2410 [10]. The primary material used in this research was the crystal structure of the human histamine $\mathrm{H}_{1}$ receptor (hHRH1) [11] (PDB ID: 3RZE) obtained from https://www.rcsb.org/structure/3RZE. The reference compound structure, i.e., ranitidine was taken from https://www.go.drugbank.com/drugs/DB00863, while the hHRH2 target sequence was obtained from https://www.uniprot.org/uniprot/P25021.

Homology modeling hHRH2 were run with YASARA-structure through the module "Homology modeling". The hHRH1 crystal structure was used as the template, which consisted of 397 amino acid residues. Alignment correction and loop modeling were performed by predicting secondary structures for target sequences using PSI-BLAST, then they were included in the PSI-Pred secondary structure prediction algorithm [12]. Five homologous models resulted from the homology modeling were then sorted by Z-score. Subsequently, YASARA-structure combines the best parts of the five models to get a hybrid model with increased accuracy beyond each contributor, shown in table 1 . A total 327 of the 397 target residues $(82.4 \%)$ were aligned with the template residues, the order identity was $24.5 \%$, and the sequence similarity was $45.0 \%$.

Table 1: Result of the hybrid model obtained the following quality Z-scores

\begin{tabular}{lcl}
\hline Check type & Quality Z-score & Comment \\
\hline Dihedrals & 0.034 & Optimal \\
Packing 1D & -0.735 & Good \\
Packing 3D & -1.437 & Satisfactory \\
Overall & -0.950 & Good \\
\hline
\end{tabular}

The selected receptor homology model was used as the target for ranitidine docking, performed 1,000 times, and iterated 25 times using the VINA method. Molecular docking simulations were run with YASARA-Structure by using the dock_run.mor command which is provided default by YASARA-Structure. Thirteen suggested ligandreceptor complexes were ordered based on the best free energy of binding. Since the molecular docking simulation provided visual information of the protein-ligand interactions [13], visual inspection played an important role in the pose selection. According to Shin et al., Asp98 in hHRH2 was fundamental for binding of essential antagonists [14]. Therefore, based on the visual inspection, the docking pose of number 12 was selected with the binding energy of$7.290 \mathrm{kcal} / \mathrm{mol}$.

Molecular dynamics (MD) simulations of the complex embedded in the membrane were then carried out to obtain an overview of the most stable ligand-receptor bond pose [16], were run with YASARAStructure by employing the md_runmembrane.mcr command which 
is provided default by YASARA-Structure. The MD simulations were carried out with the following settings: The force field AMBER14, $\mathrm{pH}$ 7.4 , temperature $298 \mathrm{~K}$, pressure 1 bar. Simulations were run at up to $100 \mathrm{~ns}$, and simulation snapshots were stored at 100 ps intervals. The snapshots were then analyzed to examine the structural stability and the free energy of binding.

The MD simulations showed that the RMSD values remained constant since 5 ns. (fig. 1. a). Delta RMSD values were calculated every $5 \mathrm{~ns}$, and the data shows that most of the times the values are less than $1 \AA$ (fig. 1. b), which indicates that the system was stable. According to Liu et al., stability is achieved if RMSD values' deviation in the last $5 \mathrm{~ns}$ in the MD simulation is less than $1 \AA ̊[15]$.

The free energy of binding in MD simulation is calculated using VINA embedded in YASARA-Structure (fig. 2). The most stable system was formed at the 838 picosecond time interval with the free energy of binding value of-9.654 $\mathrm{kcal} / \mathrm{mol}$. This system was selected and analysed further as validated virtual target (fig. 3). Thermodynamically, the best receptor-ligand interactions occur if the resulting complex has lower potential energy [16]
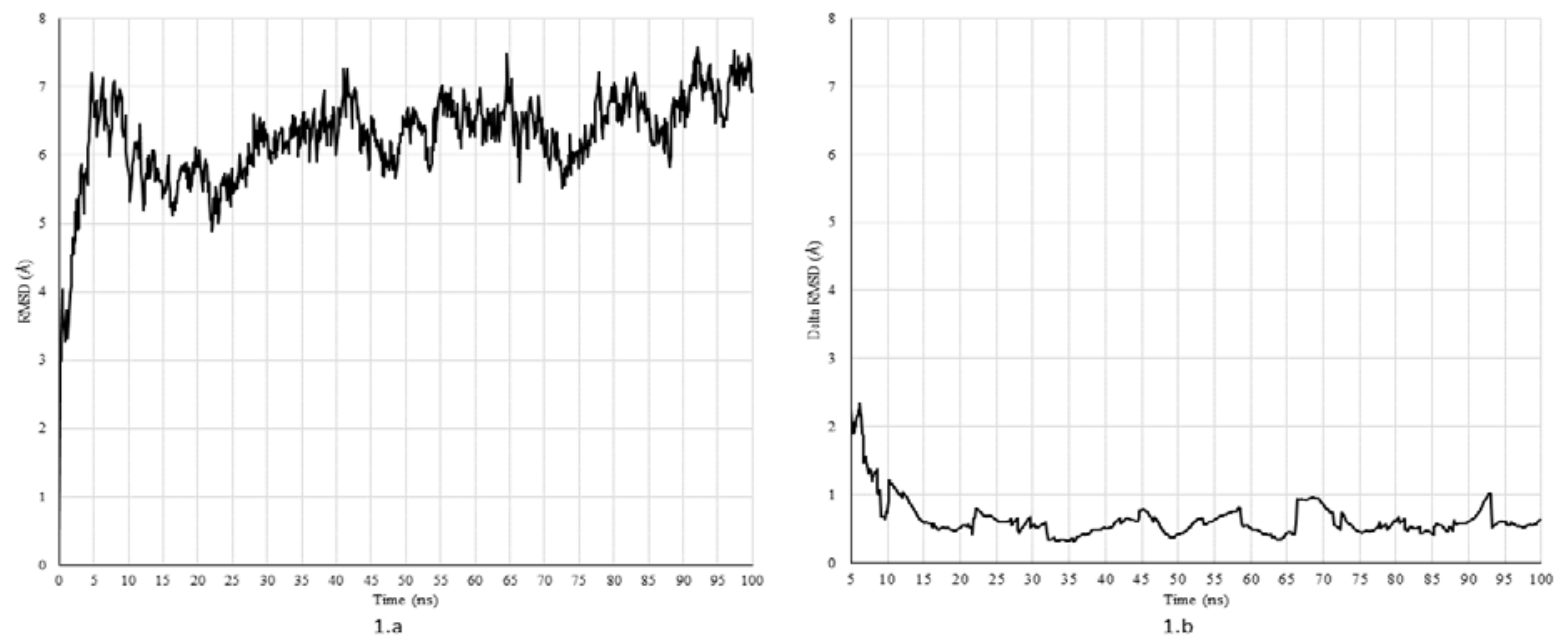

Fig. 1: a RMSD (Å) vs. Time (ns) graph, 1. b. Delta RMSD (Å) vs. Time (ns) graph

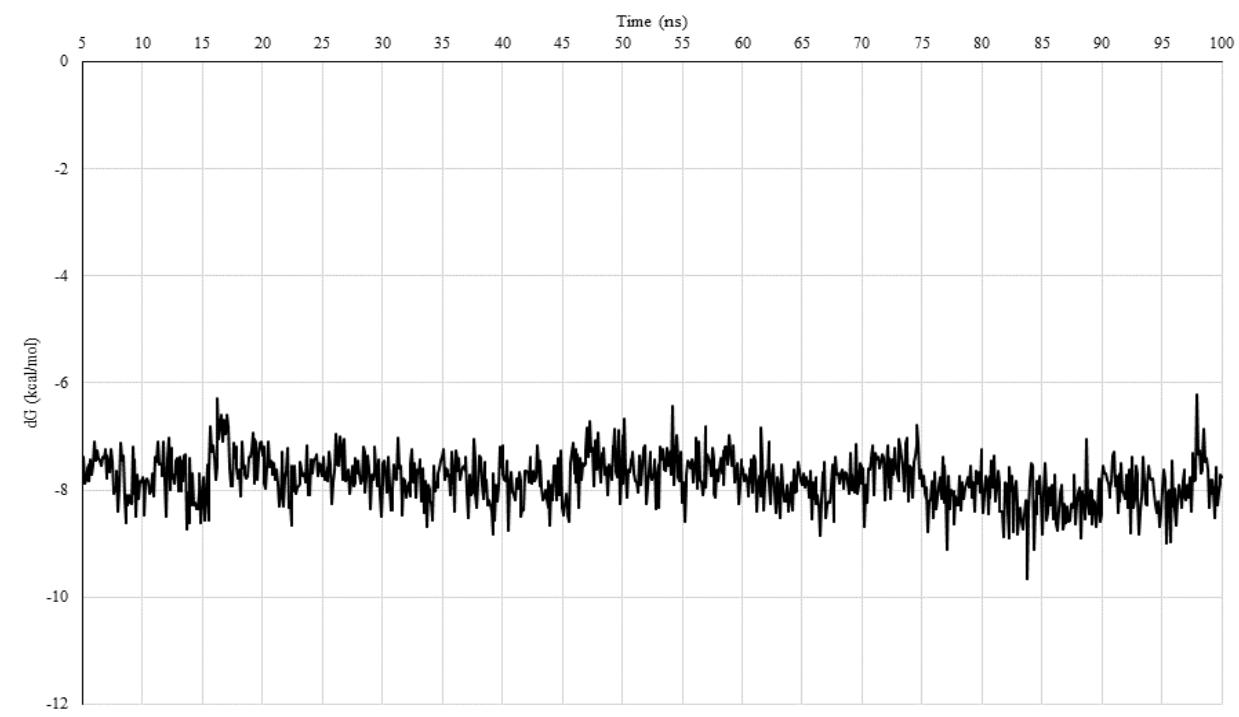

Fig. 2: The free energy of binding (kcal/mol) vs time (ns) graph

The validation was carried out by re-docking the receptor-ligand complex at snapshot 838 for 1000 times with 25 iterations. The ligand pose resulting from re-docking was compared to the reference ligand pose and the RMSD values were calculated [17]. The simulation of repeated docking 1000 times resulted in all RMSD data generated having a value of less than $2 \AA$, indicating that the resulting confidence level satisfies the rule [18]. This value is the first step in developing a quality structure-based virtual screening protocol [17] to identify histamine $\mathrm{H}_{2}$ inhibitors. Subsequently, in order to have 10 cluster systems, clusterization of the molecular dynamics simulation results was carried out by using $3.6 \AA$ as the minimum RMSD of snapshots between clusters. The clusterization was intended to provide more virtual targets for further development of structure-based screening in the discovery of hHRH2 ligands. 


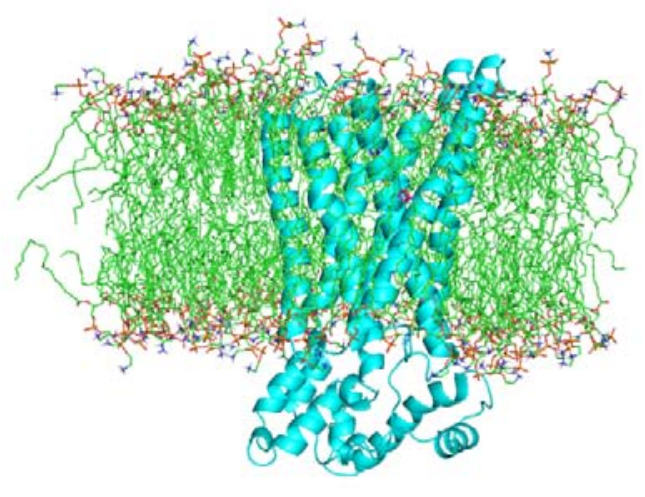

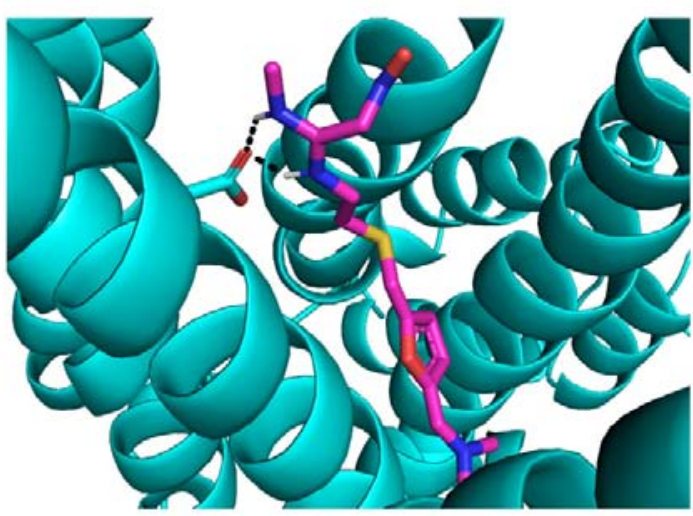

3.6

Fig. 3: a The most stable system at the 838 picosecond time interval, 3. b Visual inspection of the interaction of ranitidine to Asp98

\section{FUNDING}

This research was funded by Institute for Research and Community Services, Universitas Sanata Dharma (Research Grant Contract No. 013/Penel./LPPM-USD/II/2021).

\section{AUTHORS CONTRIBUTIONS}

G. N. conducted all the computational simulations, and E. P. I supervised the work. G. N. initiated the original draft of the manuscript. E. P. I reviewed and edited the manuscript. All authors have given approval to the final version of the manuscript.

\section{CONFLICTS OF INTERESTS}

All authors have none to declare.

\section{REFERENCES}

1. E Tiligada, M Ennis. Histamine pharmacology: from Sir Henry Dale to the 21st century. Br J Pharmacol 2020;177:1-21.

2. ML Schubert, JF Rehfeld. Gastric peptides-gastrin and somatostatin. Compr Physiol 2020;10:1-32.

3. A Lanas, FKL Chan. Peptic ulcer disease. Lancet 2017;390:1-12.

4. G Nugraha, EP Istyastono. Pembuatan protokol penapisan virtual berbasis stuktur (PVBS) untuk identifikasi ligan inhibitor reseptor platelet-activating factor (PAF-r) sebagai target terapeutik ssma menggunakan YASARA. J Ris Kim 2020;11:3542.

5. CN Cavasotto, AJW Orry. Ligand docking and virtual screening in structure-based drug discovery. Curr Top Med Chem 2007;7:1006-14.

6. A Hinchliffe. Molecular modelling for beginners. $2^{\text {nd }}$ John Wiley and Sons Ltd, Weinheim, Germany; 2008. https://doi.org/10.1365/s10337-009-1412-5.
7. L Tan, H Geppert, MT Sisay, M Gütschow, J Bajorath. Integrating structure-and ligand-based virtual screening: comparison of individual, parallel, and fused molecular docking and similarity search calculations on multiple targets. Chem Med Chem 2008;3:1-6.

8. RT Kroemer. Structure-based drug design: docking and scoring. Curr Protein Pept Sci 2007;8:1-18.

9. AR Leach, BK Shoichet, CE Peishoff. Docking and scoring. Am Chem Soc 2006;49:1-5.

10. E Krieger, G Koraimann, G Vriend. Increasing the precision of comparative models with YASARA NOVA-a self-parameterizing force field. Proteins Struct Funct Genet 2002;47:1-10.

11. T Shimamura, M Shiroishi, S Weyand, H Tsujimoto, G Winter, V Katritch, et al. structure of the human histamine $\mathrm{H} 1$ receptor complex with doxepin. Nature 2011;475:1-8.

12. DT Jones. Protein secondary structure prediction based on position-specific scoring matrices. J Mol Biol 1999;292:1-8.

13. T Lengauer, M Rarey. Computational methods for biomolecular docking. Curr Opin Struct Biol 1996;6:1-5.

14. N Shin, E Coates, NJ Murgolo, KL Morse, M Bayne, CD Strader, et al. Molecular modeling and site-specific mutagenesis of the histamine-binding site of the histamine $\mathrm{H} 4$ receptor. Mol Pharmacol 2002;62:1-10.

15. K Liu, E Watanabe, H Kokubo. Exploring the stability of ligand binding modes to proteins by molecular dynamics simulations. J Comput Aided Mol Des 2017;31:1-10.

16. G Schneider. De novo molecular design, Wiley-VCH Verlag GmbH and Co., Weinheim, Germany; 2014.

17. EP Istyastono. Construction, validation and application of structure-based virtual screening protocols to discover new cyclooxygenase-2 inhibitors. Indo J Chem 2012;12:1-5.

18. G Marcou, D Rognan. Optimizing fragment and scaffold docking by use of molecular interaction fingerprints. J Chem Inf Model 2007;47:1-13. 